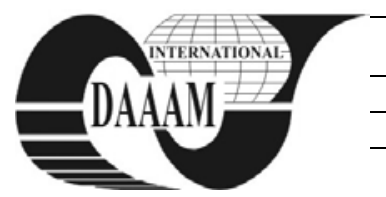

Annals of DAAAM for 2011 \& Proceedings of the 22nd International DAAAM Symposium, Volume 22, No. 1, ISSN 1726-9679 ISBN 978-3-901509-83-4, Editor B. Katalinic, Published by DAAAM International, Vienna, Austria, EU, 2011 Make Harmony between Technology and Nature, and Your Mind will Fly Free as a Bird Annals \& Proceedings of DAAAM International 2011

\title{
VISUAL AID TO DE CONFIGURATION FOR KAKURO PUZZLE SOLVING
}

\author{
BOUDNA, H[ana] \& JASEK, R[oman]
}

\begin{abstract}
One of the biggest challenges in the evolutionary optimisation is setting of evolutionary algorithm parameters. In this paper setting of Differential Evolution's configuration parameters $\mathrm{F}$ and $\mathrm{Cr}$ for solving Kakuro puzzles is tested. This adjustment is then demonstrated through a visualisation and $3 D$ maps displaying relationship between configuration parameters and appropriate solution quality.
\end{abstract}

Key words: evolutionary algorithms, differential evolution, visualisation, parameter setting

\section{INTRODUCTION}

In recent years evolutionary algorithms have gained a lot of attention regarding their potential for solving various complex optimisation problems. Number of evolutionary algorithms has been proposed for solving NP problems, e.g. (Asif \& Baig, 2009), (Greenwood, 2001), (Guturu \& Dantu, 2008). Efficiency, reliability and good behaviour of the process searching for global extremes strongly depend on algorithm's control parameters. Standard attempt in applications is to set up the values of control parameters by tuning via trial-and-error preliminary experiments. This is time-consuming and does not satisfy the user's natural requirement for quick and reliable heuristic search algorithm, which should be efficient enough to find global optimum without requiring any deeper user's knowledge.

One of the robust and powerful optimisation method designed for global optimisation is represented by Differential Evolution (DE), proposed by (Storm \& Price, 1997). There are three DE's control parameters: population size $N P$, mutation factor $F$ and crossover factor $\mathrm{Cr}$. (Brest at al., 2006) assessed the selection of control parameters and reported that efficiency and robustness of DE are much more sensitive to setting of mutation factor $\mathrm{F}$ and crossover ration $\mathrm{Cr}$ than to the value of population size $N p$. (Price and Storn, 1997) claim that choosing control parameters of $\mathrm{DE}$ is not difficult. Number of individuals has to be between $5^{*} D$ and $10 * D, F=0.5$ or increased if the population converges prematurely and values smaller than 0.4 are only occasionally effective. For $\mathrm{Cr}$, value of 0.1 is recommended as a first choice. In (Rönkkönen et al,2005) the population size, $N P$, is suggested to range from $2 D$ to $4 D$; the scale factor $F$ between 0.4 and 0.95 or choose $F=0.9$. Value of $\mathrm{Cr}$ is suggested from the interval $(0.0,0.2)$ because then each trial vector competes with a target vector (Salomon, 1997). The author of (Tvrdík, 2009) advices settings $F=0.8$ and $\mathrm{Cr}=0.5$. (Babu \& Jehan, 2003) in their paper deal with the $F$ factor up to value of 1.2.

Nowadays, requirements of many optimisation problems arise. We found, that solving of wicked Kakuro puzzle is rather difficult from the computational complexity point of view. Complexity of this pencil puzzle is said to belong to a set of NP-complete class of problems (Ruepp \& Holzer, 2010). (Davies et al., 2008) have noted that solving Kakuro puzzles is an important and useful element for construction of codes, where run totals may form a generalized type of parity check.
Best configuration depends on a particular problem and can be more difficult than expected. The main intention of presented experiments was to visualise how different values of Differential Evolution's $\mathrm{F}$ and $\mathrm{Cr}$ parameters influence its ability to solve the Kakuro puzzle.

\section{SOLVING PROCESS}

Version of differential evolution DE/Rand/1/Bin also known as "classic DE" was used for all performance tests executed. Differential Evolution operates on a population of $N P$ candidate solutions. Each individual in the population is represented by randomly generated $D$-dimensional vector (unknown white cells which are filled with a random integer values between 1 and 9). For each active individual (puzzle) three other individuals are chosen to produce an offspring. After that, mutation operation is performed. At this point, the $F$ configuration parameter gets involved; it is a constant realvalued mutation scale factor controlling mutation amplification. In order to increase the diversity of the perturbed parameter vector, crossover is applied. In the crossover operation, numbers in white cells of mutated vector and the active individual are combined. Consequently, all values in white cells are checked for being within the range from 1 to 9 . Finally, quality of newly filled Kakuro puzzle is evaluated. If a cost value of this puzzle is lower than the old one, the new one is inserted into a new generation.

\section{EXPERIMENT AND RESULTS}

The experiment consisted of solving easy and wicked Kakuro puzzles to find the control settings which provided fastest convergence and best results using DE. Population size $N P$ and number of generations Gen were picked according to the number of white and black cells. For a thorough exploration we used the following configuration of DE: a) for easy Kakuro puzzle: $N p=200$, Gen=100, b) for wicked Kakuro puzzle: $N p=800$, Gen $=500$. Both parameters $F$ and $C r$ varied between 0 and 1 with the step of 0.1 resulting in $121 \mathrm{~F}$-Cr combinations. For each $\mathrm{F}$-Cr setting, the experiment was evaluated 25 times, always with a new randomly generated initial population.

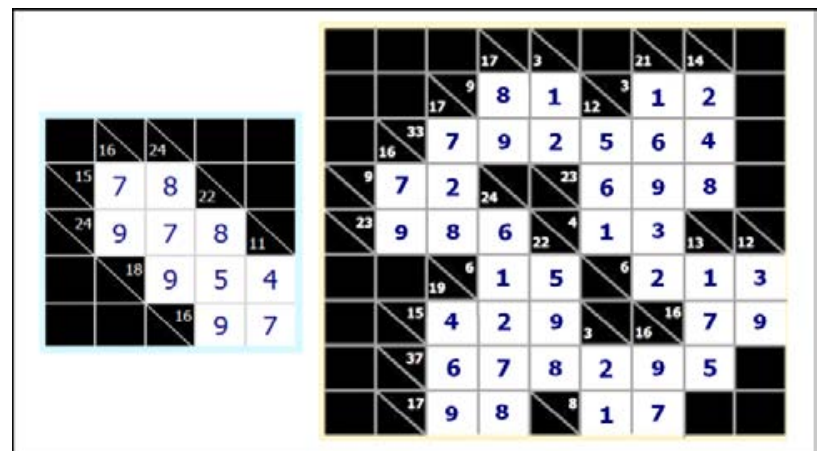

Fig. 1. Easy Kakuro (right) and wicked Kakuro (left) puzzles 
As has been demonstrated by performance maps in Figure 2, DE provided very good results for easy Kakuro puzzle when $\mathrm{F}$ parameter is set between 0.1 and 0.5 and $\mathrm{Cr}$ parameter

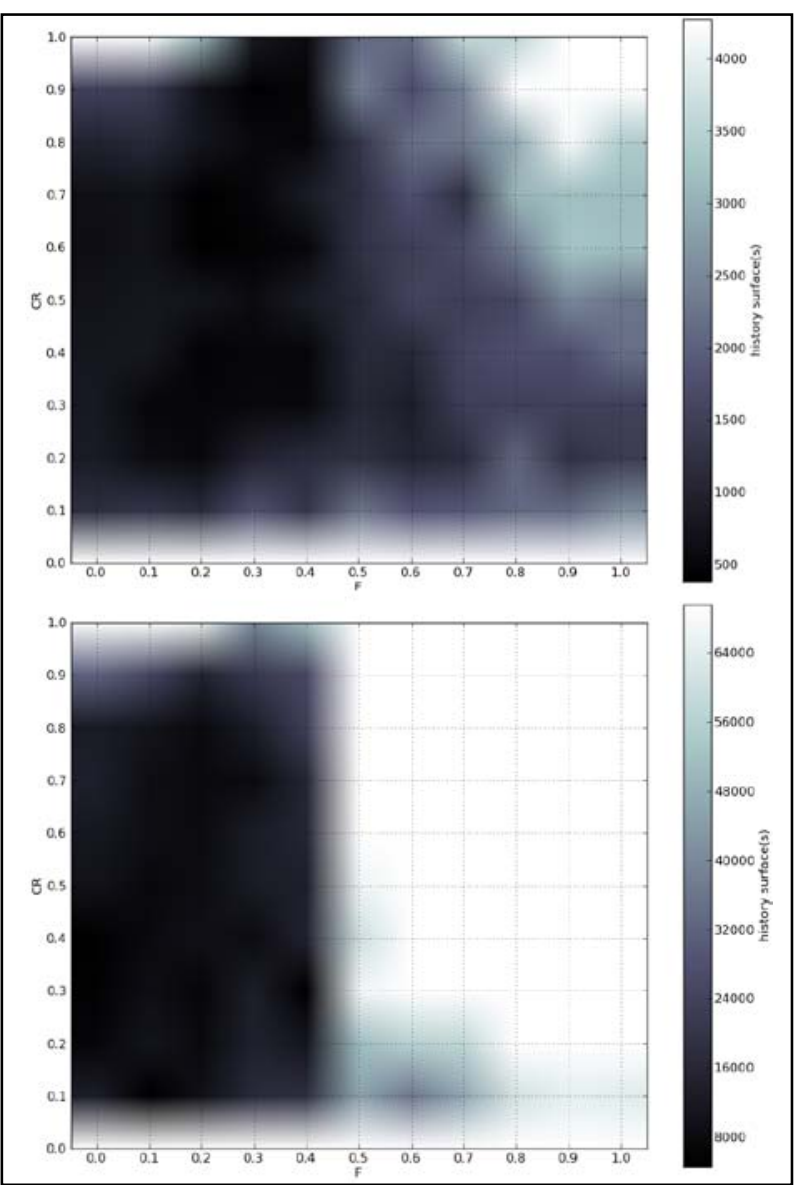

Fig. 2. Solution quality visualisation for easy (top) and wicked (bottom) Kakuro puzzles

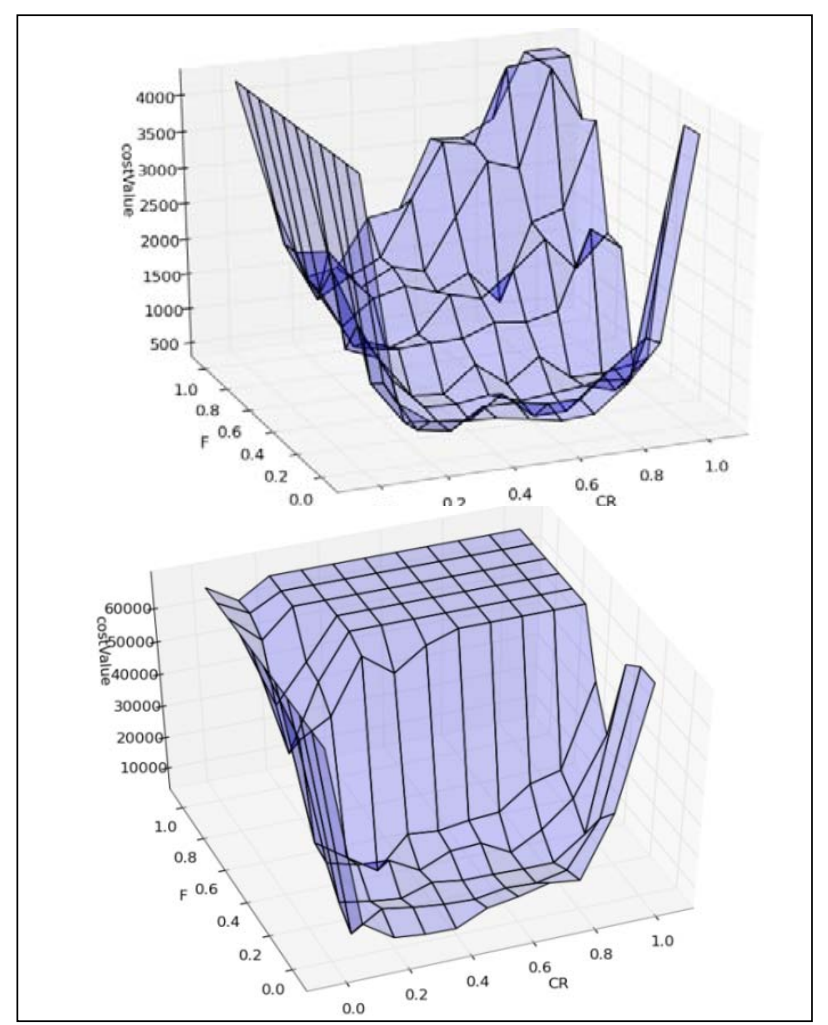

Fig. 3. 3D visualisation of gained cost value for easy (top) and wicked (bottom) Kakuro puzzles ranges between 0.2 and 0.9. However, in the case of wicked Kakuro puzzle, $\mathrm{F}$-Cr pair parameters giving us useful results lie in the range from 0 to $0.2(F)$ and from 0.4 to $0.9(\mathrm{Cr})$, respectively. Our experiment indicates that the best parameter setting for selected easy Kakuro was $F=0.2, C r=0.6$. One of the best solutions found for our wicked Kakuro puzzle was $F=0.1$ and $\mathrm{Cr}=0.7$.

\section{CONCLUSION}

Intention of the experiment was to map and visualise the influence of DE's configuration parameters $\mathrm{F}$ and $\mathrm{Cr}$ on solution quality spawned by the optimisation process. For this task sample easy and wicked Kakuro puzzles were chosen. Our results are in contrast with both recommended values as $F$ values below 0.4 and $\mathrm{Cr}$ values over 0.2 gave us the best results.

The future experiments are going to consist of comparison Differential Evolution with other evolutionary algorithms on the task of solving Kakuro puzzle problem.

\section{ACKNOWLEDGEMENTS}

The work was supported by the "internal grant agency" No. IGA/33/FAI/1/D of the Tomas Bata University in Zlín.

\section{REFERENCES}

Asif, M. \& Baig, R. (2009). Solving NP-complete problem using ACO algorithm, In: Emerging Technologies, 2009. ICET 2009. International Conference, pp.13-16, 19-20 Oct. 2009. ISBN: 978-1-4244-5630-7

Babu, B.V. \& Jehan, M.L. (2003). Differential Evolution for Multi-Objective Optimization, Proceedings of the 2003 Congress on Evolutionary Computation (CEC'2003), Vol. 4, pp. 2696-2703, IEEE Press

Brest, J.; Zumer, V. \& Maucec, M.C. (2006). Self-Adaptive Diffeential Evolution Algorithm in Constrained RealParameter Optimization, Proceedings of the 2006 IEEE Congress on Evolutionary Computation, ISBN: 0-78039487-9 , IEEE Press, pp. 215-222

Greenwood, G.W. (2001). Finding solutions to NP problems: philosophical differences between quantum and evolutionary search algorithms, In: Evolutionary Computation, 2001. Proceedings of the 2001 Congress, Vol.2, pp.815-822. ISBN: 0-7803-6657-3

Guturu, P. \& Dantu, R. (2008). An Impatient Evolutionary Algorithm with Probabilistic Tabu Search for Unified Solution of Some NP-Hard Problems in Graph and Set Theory via Clique Finding, In: Systems, Man, and Cybernetics, Part B: Cybernetics, IEEE Transactions on , Vol.38, No.3, (June 2008) pp.645-666, ISSN: 1083-4419

Jilg, J. \& Carter, J. (2009). Sudoku evolution, In: Games Innovations Conference. ICE-GIC 2009. International IEEE Consumer Electronics Society's , pp.173-185, 25-28 Aug. 2009, ISBN: 978-1-4244-4459-5

Price, K. \& Storn R. (1997). Differencial Evolution - A Simple and Efficient Heuristic for Global Optimization over Continuous Spaces, Journal of Global Optimization 11. Vol. 11. No.4. (December 1997) 341-359, Kluwer Academic Publishers, ISSN: 0925-5001

Ronkkonen, J.; Kukkonen, S. \& Price, K.V. (2005). Realparameter optimization with differential evolution, In: Evolutionary Computation, 2005. The 2005 IEEE Congress, Vol.1, pp.506-513, 5-5 Sept. 2005

Tvrdík, J. (2009). Adaptation in differential evolution: A numerical comparison, Applied Soft Computing. Vol. 9, No. 3. (June 2009) 1149-1155. Elsevier Science Publishers B. V., ISSN: 1568-4946 